\title{
Extraction of bioactive compounds from Curcuma longa L. using deep eutectic solvents: In vitro and in vivo biological activities
}

\author{
Grazielle Oliveira $^{\mathrm{a}}$, Caroline Marques ${ }^{\mathrm{a}}$, Anielle de Oliveira ${ }^{\mathrm{b}}$, Amanda de Almeida dos Santos ${ }^{\mathrm{d}}$, \\ Wanderlei do Amaral ${ }^{\mathrm{a}}$, Rafael Porto Ineu ${ }^{\mathrm{b}}$, Fernanda Vitória Leimann ${ }^{\mathrm{b}, \mathrm{c}}$, Ana Paula Peron ${ }^{\mathrm{d}}$, \\ Luciana Igarashi-Mafra ${ }^{a}$, Marcos R. Mafra ${ }^{a, *}$

\footnotetext{
${ }^{a}$ Department of Chemical Engineering, Graduate Program in Food Engineering, Federal University of Paraná, Av. Francisco Heráclito dos Santos, $n$. 100, PC 81531-980 Curitiba, Paraná State, Brazil

${ }^{\mathrm{b}}$ Post-Graduation Program of Food Technology (PPGTA), Federal University of Technology-Paraná, Campus Campo Mourão (UTFPR-CM), Via Rosalina Maria Dos Santos, 1233, CEP 87301-899 Campo Mourão, Paraná State, Brazil

${ }^{\mathrm{c}}$ Centro de Investigação de Montanha (CIMO), Instituto Politécnico de Bragança, Campus Santa Apolónia, 5300-253 Bragança, Portugal

d Biodiversity and Nature Conservation Department, Federal University of Technology - Paraná - UTFPR, Campus Campo Mourão, via Rosalina Maria dos Santos, 1233,
} \\ CEP 87301-899 Campo Mourão, Paraná State, Brazil
}

\section{A R T I C L E I N F O}

\section{Keywords:}

Antioxidant

Antibacterial

Iron-chelating

Cholinesterase

Cellular level toxicity

\begin{abstract}
A B S T R A C T
In this work, deep eutectic solvents (DES-based menthol and cholinium chloride) and the ethanol, temperature, and times were selected to extract bioactive compounds from the rhizome, leaves, and flowers Curcuma longa L., using ultrasound-assisted extraction. Analyzes antioxidant, flavonoids, antimicrobial, chelation $\mathrm{Fe}^{2+}$, inhibition of the cholinesterase's enzymes, cytotoxicity, and genotoxicity in Allium cepa cells were performed. The extracts showed results of iron chelation and antibacterial. Curcuma flowers and leaves' extracts inhibited food spoilage bacteria with values above $45 \%$, with substantial iron-chelating activity above $50 \%$. Extracts obtained by DES based on menthol and lactic acid exhibited a high percentage of inhibition of acetyl and butyryl cholinesterase. In contrast, flower extracts obtained by menthol and acetic acid showed low inhibition of cholinesterase enzyme activity. No extract showed cytotoxicity and genotoxicity. Biological activities showed a high potential for the application of these extracts in the food and pharmaceutical industries.
\end{abstract}

\section{Introduction}

The Curcuma longa L., popularly called "turmeric", is a plant that originated in Asia that has been disseminated to several countries over time (Scartezzini \& Speroni, 2000). The plant has oblong or ovate leaves, light green, and a pungent, spicy aroma, with flowers ranging from lilac to white color (Chan et al., 2009). The rhizome powder is yellowish-orange in color, with a characteristic odor and flavor (Soni, Patel, \& Pradesh, 2011). Curcuma longa L. rhizomes' powder is widely used as a food coloring in mustards, dehydrated soups, and formulations for seasoning, such as curry.

There is currently a wide variety of products marketed with varying concentrations of bioactive compounds extracted from turmeric (Chatzinasiou, Booker, Heinrich, Maclennan, \& Mackonochie, 2019). Numerous studies and review articles evidenced the high capacity of bioactive compounds present in Curcuma longa L. to act as antioxidant, anti-inflammatory, antibacterial, and anti-carcinogenic agents. Also, several studies report its use as herbal medicine, helping to prevent diseases and premature aging (Bavarsad, Matbou, Saadat, \& Barreto, 2019; Grover, Shah, Khullar, Gupta, \& Behl, 2019; Kwiecien, Magierowski, Majka, \& Ptak-belowska, 2019; Salehi et al., 2019).

The extraction of antioxidant compounds present in Curcuma longa L. is usually carried out using conventional solvents such as ethanol, methanol, and acetonitrile (Braga, Caroline, Vieira, \& De Oliveira, 2018; Pal et al., 2020). To achieve a cleaner, non-toxic, and biocompatible extraction processes that generate less damage to the environment and bioactive compounds, a new class of green solvents known as deep eutectic solvents (DES) have emerged in recent years. DES are formed by the combination of a hydrogen bond donor (HBD) and a hydrogen bond acceptor (HBA), producing a mixture with a substantial deviation from ideality (Abbott, Capper, Davies, Rasheed, \& Tambyrajah, 2003; Dai, Van Spronsen, \& Witkamp, 2013; Martins,

\footnotetext{
* Corresponding author.

E-mail address: marcos.mafra@ufpr.br (M.R. Mafra).
} 
Pinho, \& Coutinho, 2018). The combination of HBD and HBA can be tuned according to the required application (Makoś, Słupek, \& Gębicki, 2020). Thus, DES can be termed as a designer solvent, i. e. it can be prepared according to the application of interest, such as the extraction of bioactive compounds (Bajkacz \& Adamek, 2017; Khezeli, Daneshfar, \& Sahraei, 2016).

Currently, choline chloride is still the most used quaternary ammonium salt as HBA in the synthesis of DES (Vilková, Justyna, \& Andruch, 2020; Zhang, Oliveira, Royer, Royer, \& Jérôme, 2012), mainly for hydrophilic DES. However, recently, menthol and betaine have appeared with important HBA due to the hydrophobic character conferred to the produced solvent (Florindo, Branco, \& Marrucho, 2017; Ribeiro, Florindo, Lucas, Coelho, \& Marrucho, 2015). In combination with HBAs, the HBDs can be alcohols, carboxylic acids, sugars, and amines, or any other compound capable of creating hydrogen bonds (Florindo et al., 2017; Ribeiro et al., 2015; Vilková et al., 2020; Zhang et al., 2012). In addition to the solvent characteristics, for efficient extraction, some process parameters are critical in this scenario, such as solute/solvent ratio, the temperature of extraction, and time (Mandal, Dewanjee, Sahu, \& Mandal, 2009; Patil \& Rathod, 2020; Shirsath et al., 2017).

Although some studies have already evaluated the extraction of bioactive compounds from turmeric, the use of green solvents such as DES is still little explored for this species (Altunay, Elik, \& Gürkan, 2020; Aydin, Yilmaz, \& Soylak, 2018; Liu et al., 2019). Consequently, the application of these extracts in the development of products of biological origin is still scarce. Thus, this work aims to evaluate the use of hydrophilic (Cholinium chloride + Lactic acid and Cholinium chloride + Acetic acid) and hydrophobic DES's (Menthol + Lactic acid, Menthol + Lauric acid, and Menthol + Acetic acid), a recent class of green solvents, in the extraction of bioactive compounds present in Curcuma longa L plant. Extraction using ethanol was carried out for comparison. Evaluation of temperature $\left(35,45\right.$ and $\left.55{ }^{\circ} \mathrm{C}\right)$ and extraction times $0.5,1,1.5,2,2.5$ and $3 \mathrm{~h}$. Moreover, the extracts and DES were tested for bioactivities: Antioxidant capacity (DPPH and FRAP methods), flavonoid content, antibacterial and iron-chelating activities, the inhibitory activity of the acetyl, and butyryl cholinesterase enzymes, and cytotoxic and genotoxic potential in A. cepa root meristems. Thus, this work should establish safer bases for the use of these extracts in the development of new products in food, cosmetics, and pharmaceuticals.

\section{Material and methods}

\subsection{Material and preparation of sample and DES}

\subsubsection{Material}

The details regarding all reagents used in this work are described in the supplementary material.

\subsubsection{Preparation of rhizomes, leaves, and flowers of Curcuma longa L. samples}

The rhizomes, leaves, and flowers of Curcuma longa L. were collected from specimens grown in Piraquara, Paraná State, Brazil (S $25^{\circ} 503$ ' $261^{\prime \prime}$ and W 49 $003^{\prime}$ '917"). The samples were cleaned with deionized water and dried in an air circulation oven (FABBE $\left.{ }^{\circledR}\right)$ withtemperature control $\left(45 \pm 3^{\circ} \mathrm{C}\right.$ ) (Borah, Hazarika, \& Khayer, 2015), for a period of $24 \mathrm{~h}$. Finally, the samples were ground in a knife mill, and the powder produced was classified in 30 mesh sieves and stored in vacuum packaging, kept under refrigeration $\left(6{ }^{\circ} \mathrm{C} \pm 2{ }^{\circ} \mathrm{C}\right)$. The powders' density, 2.691, 1.953 and $0.351 \mathrm{g.cm}{ }^{-3}$, rhizome, leaves, and flowers, respectively, was measured according to the methodology described by Kirikta and co-workers (Kirikta, Mehmet, Eslek, \& Kirikta, 2018) with modifications (further details are described in the supplementary material).

\subsubsection{Preparation of deep eutectic solvents (DES)}

The preparation of the deep eutectic solvents (DES) was performed by method described by Dai and co-workers (Dai et al., 2013). Cholinium chloride and menthol were used as HBAs and the lauric, acetic, and lactic acids as HBDs. The reagents were weighed and kept under agitation in a thermostatic bath (Dubnoff Ethik Technology) at a temperature of $70{ }^{\circ} \mathrm{C}$ until a transparent and homogeneous solution was obtained. Table 1 presents the information about the DES employed in this work. Information regarding the reagents used in the preparation of DES are shown in Table S1 (see supplementary material).

\subsection{Selection of solvent, temperature, and time}

\subsubsection{Experimental design}

The samples (dried and ground) were individually mixed in the solvents (5 DES and ethanol) in a 1:20 ratio $(w / w)$ and packed in dark bottles. The mixtures were immersed in an ultrasonic bath at 50 to $60 \mathrm{~Hz}$ (FS30D, Fisher Scientific Co.). The temperature range used was 35 to $55{ }^{\circ} \mathrm{C}$, with a temperature deviation of $\pm 2{ }^{\circ} \mathrm{C}$. The ultrasound bath temperature was maintained with the aid of a thermostatic bath, using a rotary pump, the temperature is measured by a thermometer during the analyses. After all evaluations, the final extracts were centrifuged (Thermo Scientific, Microcentrifuge Heraeus ${ }^{\mathrm{TM}}$ Fresco $^{\mathrm{TM}}$ 21) at 9500 rpm for $3 \mathrm{~min}$.

Initially, to select the outstanding solvents, a first CRD (Complete Randomized Design) (Marques et al., 2020), was applied, with one treatment or variable (solvent), in six levels, at the temperature of $35{ }^{\circ} \mathrm{C}$ per $1 \mathrm{~h}$. Considering the three replicates, there were 18 observations for each part of the plant. Then, a second CRD was performed to assess the extraction temperature. Two solvents (Men:Lac and Men:Ac) and four temperatures $\left(25,35,45\right.$, and $\left.55^{\circ} \mathrm{C}\right)$ at a fixed time $(1 \mathrm{~h})$ were evaluated in this CRD, totaling 24 observations for each part of the plant. The extraction temperature of $45{ }^{\circ} \mathrm{C}$ showed the best performance and was selected for the last stage. Finally, a third CRD was applied to evaluate the extraction time. For this, two treatments (solvent and time) were used. Two solvents (Men:Lac and Men:Ac), one temperature $\left(45^{\circ} \mathrm{C}\right.$ ) and six extraction times $(0.5,1.0,1.5,2.0,2.5$ and $3 \mathrm{~h})$ were applied with 36 observations total.

\subsubsection{DPPH, FRAP, and flavonoids total analyzes}

DPPH, FRAP, and flavonoids analyses were performed to select the optimal conditions of extraction. All analyses were carried in triplicate. Details regarding the description of the methods can be found in the supplementary material.

\subsection{Biological activities}

After selecting the optimal conditions of extraction, some bioactivities were evaluated, are they: the iron-chelating, antibacterial potentials, percentage of inhibition of acetyl and butyryl cholinesterase enzyme's activity, cytotoxicity, and genotoxicity in $A$. cepa cells.

\subsubsection{Iron chelation}

The chelating activity of the $\mathrm{Fe}^{2+}$ ion was accessed in agreement with Ak Tuba (2008) and Gülçin (2006) with slight modifications to adapt the DES samples. The samples were diluted (1:5) in distilled water $(1 \mathrm{~mL}$

Table 1

Information related to the DES used in the work.

\begin{tabular}{lll}
\hline Abbreviation & Mixture & Molar ratio \\
\hline Men:Lac & Menthol + Lactic acid & $1: 2$ \\
Men:Lau & Menthol + Lauric acid & $2: 1$ \\
Men:Ac & Menthol + Acetic acid & $1: 1$ \\
[Ch]Cl:Lac & Cholinium chloride + Lactic acid & $1: 2$ \\
[Ch]Cl:Ac & Cholinium chloride + Acetic acid & $1: 2$ \\
\hline
\end{tabular}


total) and read at a wavelength of $562 \mathrm{~nm}$. The iron-chelating activity was determined in percentage, according to Eq. (1), moreover expressed in $\mathrm{mg}$ EDTA. $\mathrm{mL}^{-1}$.

Chelating capacity $\mathrm{Fe}^{2+} \%=\left[\left(\frac{\mathrm{Abs}_{\text {Control }}-\mathrm{Abs}_{\text {sample }}}{\mathrm{Abs}_{\text {Control }}}\right)\right] * 100$

\subsubsection{Antibacterial activity}

The methodology followed the instructions of CLSI et al. (2017). The strains of bacteria were selected due to their importance in food processing: (Listeria monocytogenes (ATCC ${ }^{\circledR} 7644^{\mathrm{TM}}$ ), Escherichia coli (ATCC $₫ 25922^{\mathrm{TM}}$ ), Clostridium perfringens (ATCC $₫ 13124^{\mathrm{TM}}$ ), Salmonella sp. (ATCC $® 13076^{\mathrm{TM}}$ ), and Staphylococcus aureus (ATCC $® 25923^{\mathrm{TM}}$ ). The microbial inhibition was determined by measuring the inhibitory halos, in millimeters, with a digital caliper. The percentage of inhibition was calculated based on the antibiotic halos found for each bacteria. The halos were labeled as $\mathrm{S}=$ susceptible $>18 \mathrm{~mm}$; $\mathrm{I}=$ intermediate 13 to 17 $\mathrm{mm}$ and $\mathrm{R}=$ resistant $<12 \mathrm{~mm}$, according to the minimum inhibition ranges.

\subsubsection{In vitro cholinergic activity}

The selected extracts were applied to evaluate the activity inhibition of the enzymes acetylcholinesterase (AChE) and butyryl cholinesterase (BChE) using the method described by Ellman and co-workers (Courtney \& Francisco, 1961), with modifications (Hammond \& Forster, 1989; Dohi Satomi \& Terasaki Masanori, 2009), using Drosophila melanogaster homogenate as enzyme source (S1) for BChE and electric eel for AChE. The absorbance of samples (extracts diluted $100 \times$ in methanol) reading was taken at $405 \mathrm{~nm}$ (for control), with posterior $30 \mathrm{~min}$ incubation in dark conditions and final reading at $405 \mathrm{~nm}$ (Thermoplate TP-Reader). The inhibition percentage was determined by Eq. (2).

Inhibition $(\%)=100-\frac{A B S_{\text {sample }}}{A B S_{\text {control }}} \times 100$

$A b s_{\text {sample }}$ is the absorbance of the sample containing DES + turmeric rhizome, leaves, or flower, and $A b s_{\text {control }}$ is the absorbance of the control without a sample (control).

\subsubsection{Cytotoxicity and genotoxicity test in root meristem cells of Allium cepa $L$.}

The A. cepa assays were executed using pesticide-free seeds (Baia Periforme variety) and purchased from Isla (Isla Sementes Ltda., Brazil), according to Fiskesjö (1993) method. For each studied group, ten seeds of $A$. cepa were continuously overexposed in an aqueous solution $(n=3)$. The germination took place at $23 \pm 2{ }^{\circ} \mathrm{C}$ with a photoperiod of $12: 12 \mathrm{~h}$ during $96 \mathrm{~h}$. Both seeds and radicles were exposed to the extracts and DES. A negative control group based on seeds dipped in distilled water was considered. The roots were collected every $24 \mathrm{~h}$, and for each exposure time, 3000 cells were evaluated, totaling 9000 cells per evaluated treatment group. Positive control was prepared with methyl methane sulfonate (MMS), a known cytotoxic and genotoxic substance to the $A$. cepa test system, at the concentration $4.10^{-4}$ mol. $\mathrm{L}^{-1}$.

All roots collected during the experiment were fixed in 3:1 Carnoy solution (ethanol:acetic acid) up to $24 \mathrm{~h}$. For estimates of the mitotic index, cells in interphase, prophase, metaphase, anaphase, and telophase were counted to determine the cytotoxic potential. The mitotic index or cell division index was calculated via Eq. (3):

$M I=100 \frac{n_{\text {mitosis }}}{n_{\text {total }}}$

The genotoxic potential was assessed by frequency of cell alterations such as micronuclei, colchicine metaphases, anaphase and telophase bridges, gene amplifications, cells with adhesions, nuclear buds, and multipolar anaphases. Analysis of variance (ANOVA) was applied as the Fisher's Least Significant Difference (LSD test), accessing mean differences $(p<0.05)$.

\section{Results and discussion}

\subsection{Effect of different parameters on ultrasound assisted-extraction}

As previously described, the selection of optimal conditions was carried out in three stages, presented below.

\subsubsection{Selection of solvents}

Initially, six solvents' ability for the extraction of bioactive compounds from the rhizomes, leaves, and flowers of Curcuma longa L. was assessed. Three hydrophobic DES (menthol + lactic acid, menthol + lauric acid, and menthol + acetic acid), two hydrophilic DES (cholinium chloride + acetic acid and cholinium chloride + lactic acid), and ethanol as a conventional solvent were evaluated (Table 1). The hydrophobic and hydrophilic DES selected in this work was based on data already established in the literature that guarantee that the solvents present the simple synthesis and sufficient stability to be used in the evaluated extraction processes. Moreover, pure solvents were analyzed by DPPH, FRAP, and flavonoid analyses to evaluate possible interferences; however, no activities were noted.

In Fig. 1, the results of DPPH, FRAP, and flavonoids analyses of extracts from six different solvents can be observed. The outstanding solvents, with a significant differences from others, were the hydrophobic DES ones: Men:Lac and Men:Ac, as they alternated as better statistical results for the three parts of the plant.

Ethanol, a conventional solvent widely used for the extraction of bioactive compounds present in Curcuma longa L. (Liu et al., 2019; Patil \& Rathod, 2020; Soni et al., 2011), showed less capacity to extract bioactive compounds (Fig. 1), differing statistically from the other solvents. For rhizome, in the analysis of DPPH and flavonoids, ethanol showed a superior extraction efficiency only concerning Men:Lau. Referring to FRAP analysis, the values were higher only than the results found for [Ch]Cl:Lac. Regarding the leaves, in the analyses of DPPH and FRAP, ethanol showed a superior extraction efficiency only concerning Men:Lau, and for flavonoids, it presented the lowest values. Through ANOVA analysis, it was possible to notice that ethanol presented the lowest extraction capacity for the flower compared to other solvents.

In the rhizomes of the Curcuma longa L., three main hydrophobic curcuminoids are found: curcumin (65 wt\%), desmethoxycurcumin (25 $\mathrm{wt} \%$ ), and bisdemethoxycurcumin (13 wt\%) (Nelson et al., 2017). It can help to understand the outstanding performance of hydrophobic solvents. Based on the variance (ANOVA) analysis, the observed statistical difference allows affirming that the two hydrophobic solvents evaluated, Men:Lac and Men:Ac, present superior performances to the other evaluated solvents. Regarding the main physical and chemical properties, it is important to note that both solvents have densities close to that of water (1038.0 and $935.0 \mathrm{~kg} . \mathrm{m}^{-3}$, respectively, at $25^{\circ} \mathrm{C}$ ) (Makoś et al., 2020). On the other hand, the viscosity of the two hydrophobic DES are quite distinct from each other (370.9 and $11.3 \mathrm{mPa}$, Men:Lac and Men: Ac, respectively), and both are considerably higher than that of water (0.89 mPa) (Makoś et al., 2020). This characteristic demonstrates the nature and intensity of the molecular interactions between the DES developers (HBA and HBD) on the solvent's physicochemical properties. Despite the high viscosity of the two DES, it is possible to observe that the extraction process was not significantly affected. It should be noted that the extraction temperature $\left(35^{\circ} \mathrm{C}\right)$ and the use of an adequate stirring contributed to the minimization of mass transfer problems resulting from the high viscosity of the solvent.

\subsubsection{Selection of extraction temperature}

In Fig. 3, it is noticeable the influence of the temperature used to extract bioactive compounds in DPPH, FRAP, and flavonoids data, highlighting $45^{\circ} \mathrm{C}$ standing out as the highest statistical values for both solvents. The influence of temperature during extraction can be noted in rhizomes and leaves more intensely than in the flower data. Flower extracts samples had the lower antioxidant capacity and flavonoid 

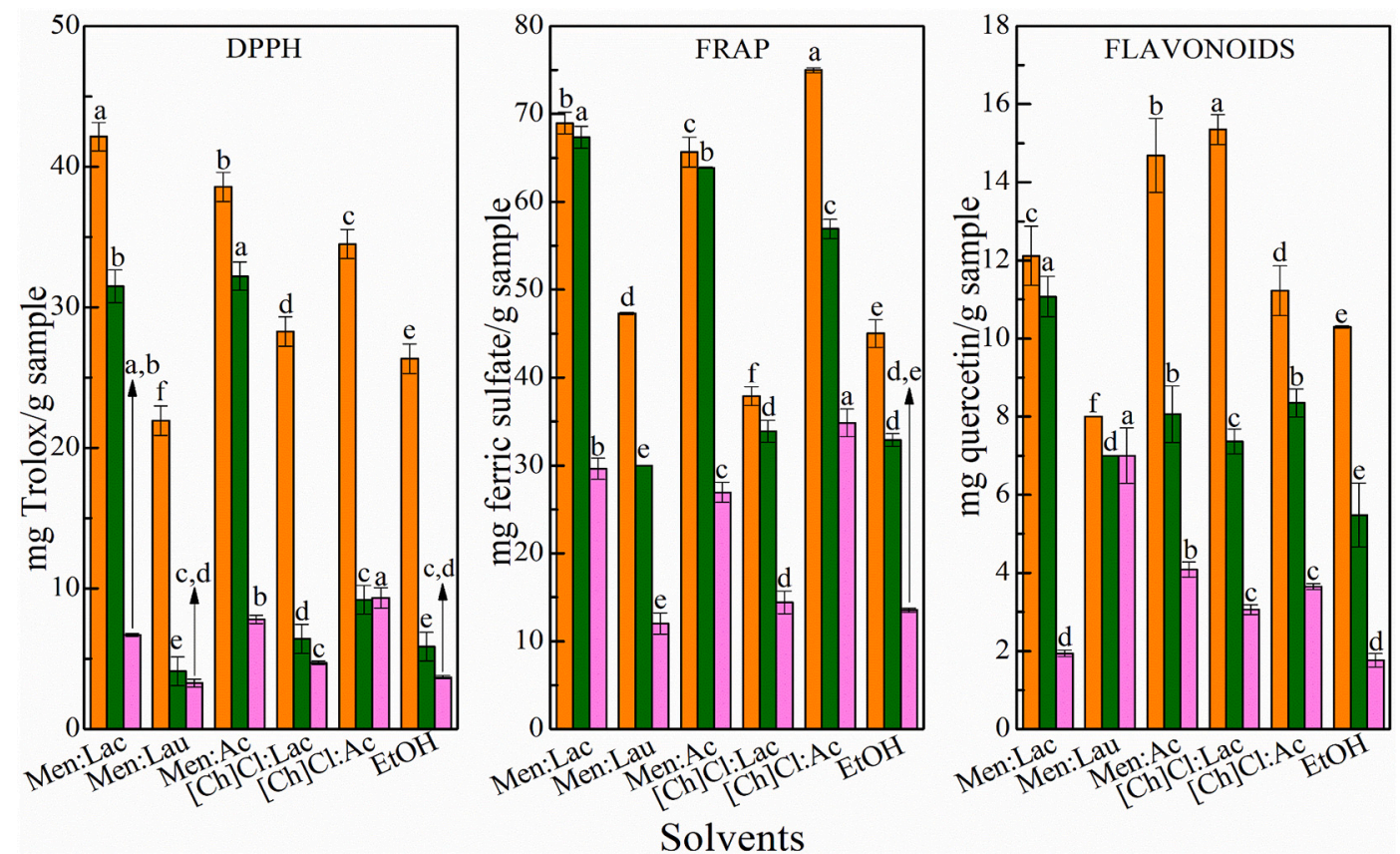

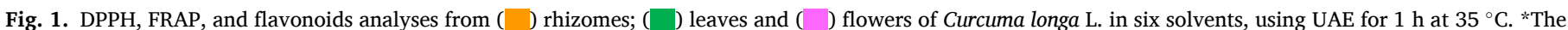

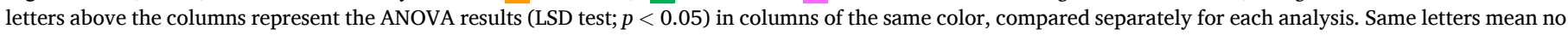
significant difference.

content when compared to those containing rhizomes and leaves. Also, it is already known that the increase of temperature during the extraction reduces the viscosity of solvents, mainly enhancing the DES

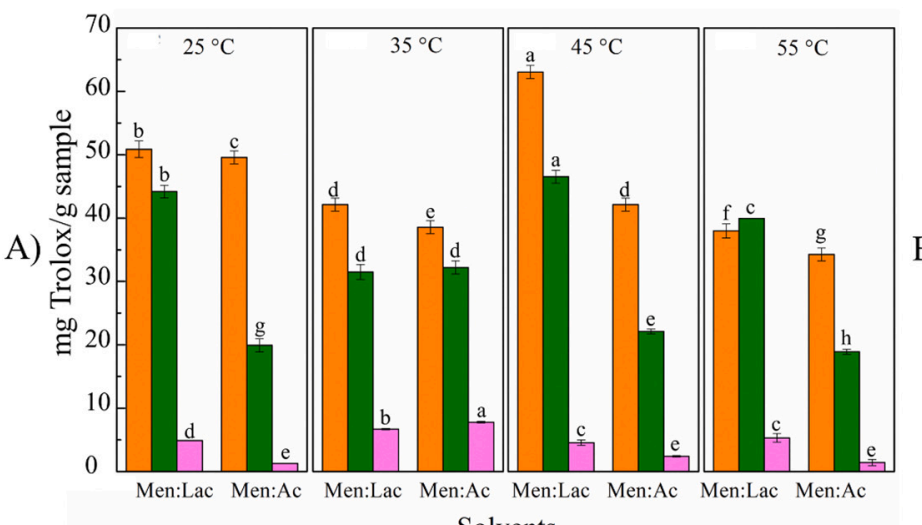

Solvents
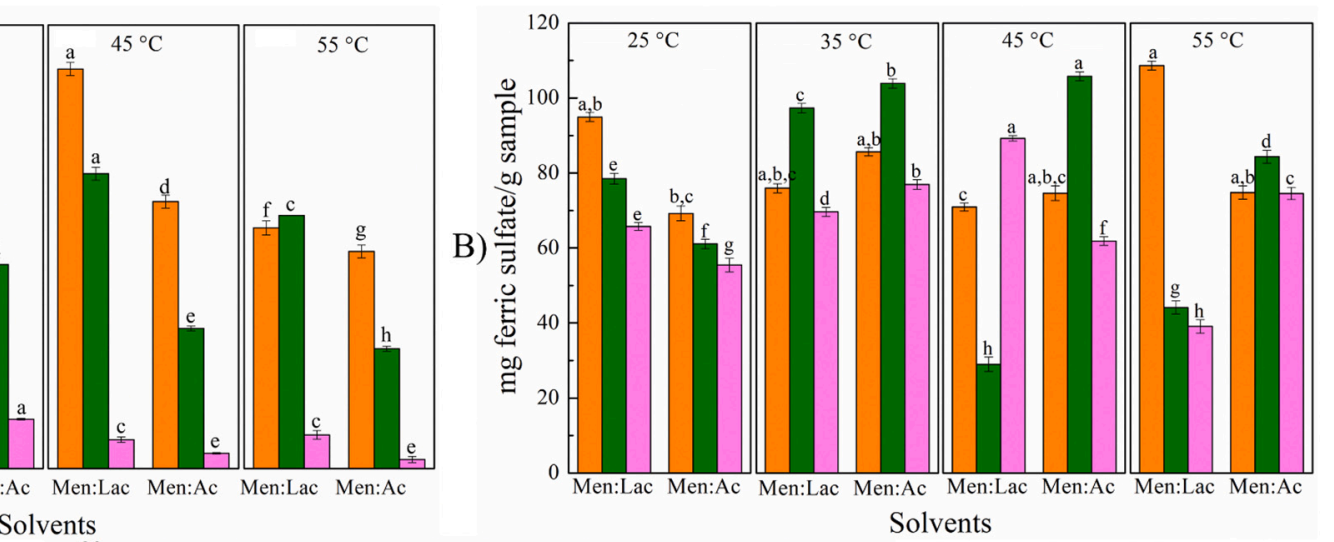

Solvents potential of extraction, increasing their diffusivity in the solid (Ribeiro et al., 2015).

In the present findings, it was possible to see a peak at $45{ }^{\circ} \mathrm{C}$ with

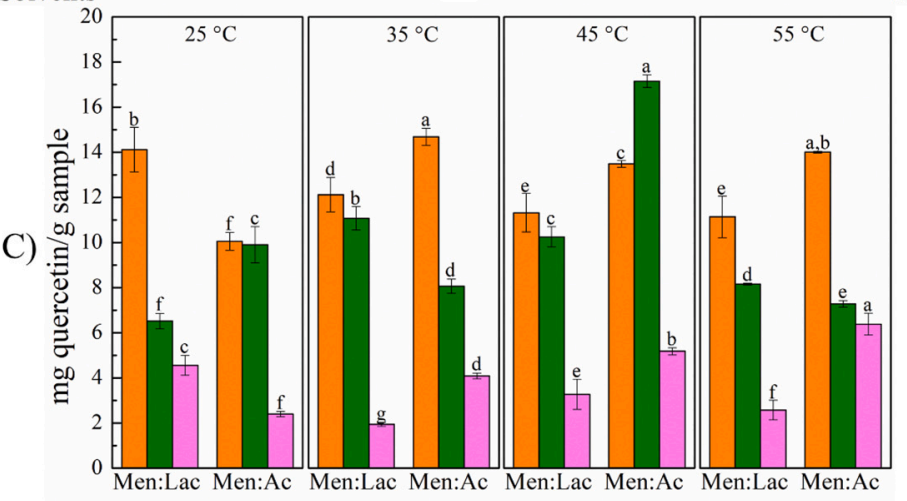

Solvents

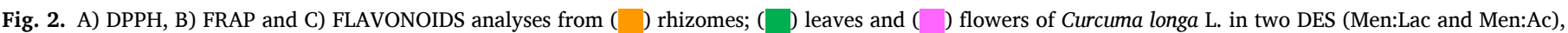

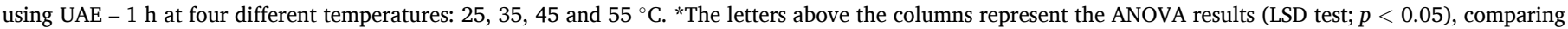
columns of the same color for all temperatures. Same letters mean no significant difference. 
potential degradation already at $55{ }^{\circ} \mathrm{C}$, clearly for DPPH (Fig. 2a) and flavonoids (Fig. 2b). According to Skerget and co-workers (Skerget, Perko, \& Ravber, 2015), at temperatures higher than $50{ }^{\circ} \mathrm{C}$, occurs decomposition of curcuminoids and loses stability. Therefore, at this stage, the temperature of $45{ }^{\circ} \mathrm{C}$ was selected to perform the time kinetics.

\subsubsection{Evaluation of extraction kinetics (time effect)}

In the third part of this study, the extraction kinetics was carried out. The extraction was evaluated at intervals of $30 \mathrm{~min}$ up to the limit of $3 \mathrm{~h}$, considering two solvents (Men:Lac and Men:Ac) and an extraction temperature $\left(45^{\circ} \mathrm{C}\right)$. Fig. 3 shows the results of DPPH, FRAP, and flavonoids, respectively, for rhizomes, leaves, and flowers, exhibiting the kinetics profile.

In Fig. 3, for the three analyzes and two solvents, through ANOVA, a maximum extraction in $3 \mathrm{~h}$ for rhizomes and $2 \mathrm{~h}$ for leaves, $3 \mathrm{~h}$ for flowers extracted with Men:Lac and $2 \mathrm{~h}$ Men:Ac. The reductions in DPPH, FRAP, and flavonoid values observed in the longest extraction times $(3 \mathrm{~h})$, mainly for some extracts obtained from leaves and flowers, are due to the possible degradation of bioactive compounds subjected to long periods of exposure to ultrasound. Thus, the biological analyzes presented below were performed using the following extraction parameters: Two DES (Men:Lac and Men:Ac); the temperature at $45^{\circ} \mathrm{C}$ and time from 2 to $3 \mathrm{~h}$.

\subsection{Biological potentials in vitro and in vivo}

\subsubsection{Iron chelating capacity}

The iron-chelating activity is not usually performed in extracts, although it is significant to food and cosmetic/pharmaceutical industries. The metal chelation means food enrichment, protection of the metabolism and skin against heavy metals, and the recovery of environments (water, soil, industrial waste) contaminated by metals (Cunha et al., 2019).

Fig. 4 presents the iron-chelating capacities for extracts using Men: Lac and Men:Ac solvents, as well as for the pure DES, which showed high

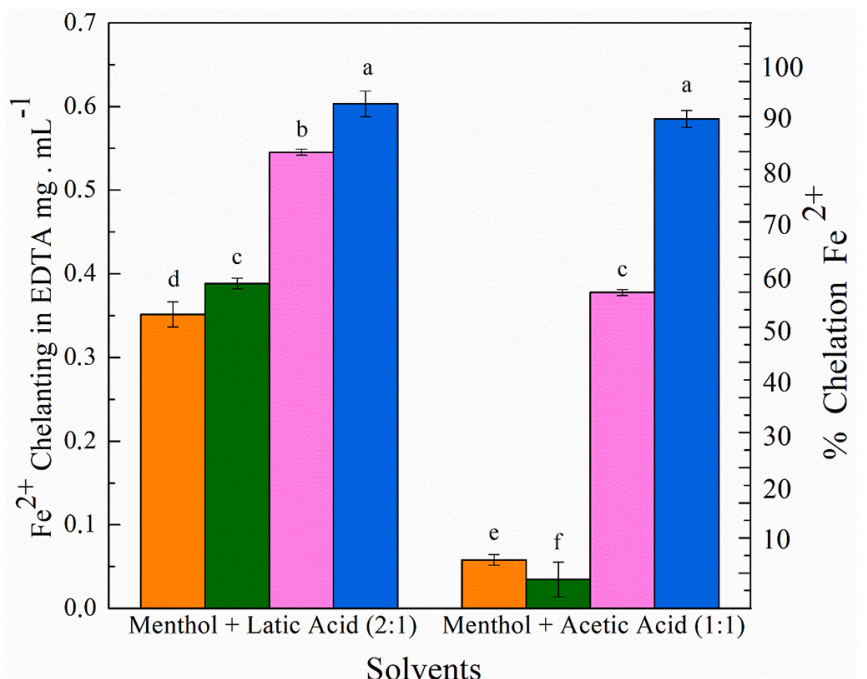

Fig. 4. Iron chelating capacity of the $(\square)$ rhizomes; $(\square)$ leaves $(\square)$ flowers extracts of Curcuma longa L. and ( $\square$ pure DES. The extracts were obtained using UAE at $45{ }^{\circ} \mathrm{C}$ and time of 2 to $3 \mathrm{~h}$. ${ }^{*}$ The letters above the columns represent the ANOVA results (LSD test; $\mathrm{p}<0.05$ ) comparing the columns for both solvents. Same letters mean no significant difference.
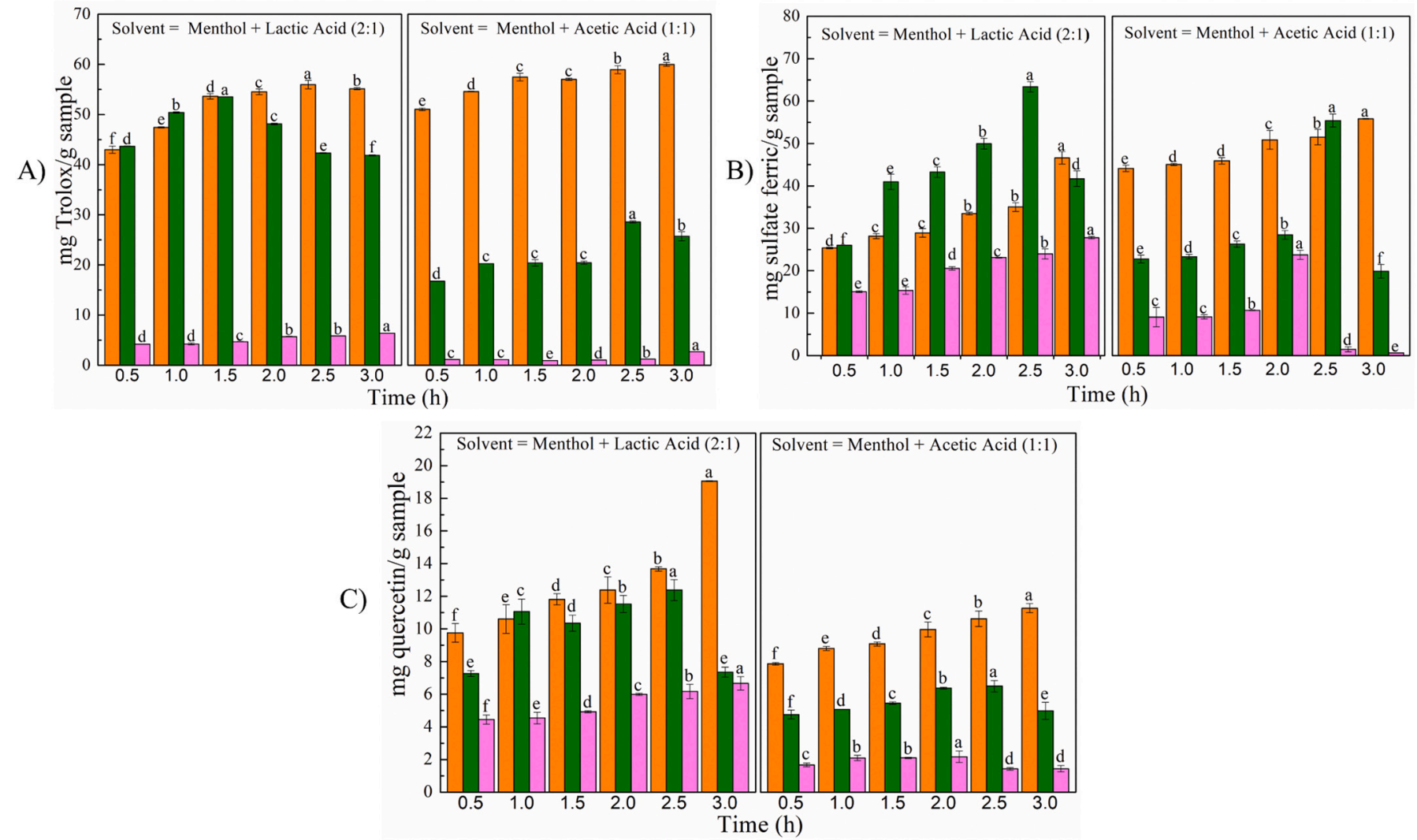

Fig. 3. A) DPPH, B) FRAP and C) FLAVONOIDS analyses from ( $\square$ ) rhizomes; ( $\square$ ) leaves and ( $\square$ ) flowers of Curcuma longa L.; using UAE at $45^{\circ} \mathrm{C}$ in different times: $0.5,1,1.5,2,2.5$ and $3 \mathrm{~h}$. *The letters above the columns represent the results of ANOVA (LSD test; $p<0.05$ ) comparing the columns of the same color for each solvent separately. Same letters mean no significant difference. 
performance for this analysis. Concerning extracts, Men:Lac ones exhibited significantly superior results from those with Men:Ac DES. In Fig. 4, it became evident that pure DES stood out in the activity of iron chelation. As the solvents showed a greater chelating capacity when compared to the extracts, there may be a relationship with the bioactive compound's occupation of chelating sites in the solvent, which consequently reduced the iron's chelating capacity. It can be highlighted the extract containing DES + flower sample, even with the lowest antioxidant activities and concentration of flavonoids.

Moreover, both pure DES achieved the highest results, with values above $95^{\mathrm{a}} \%$ [Men:Lac] and $90^{\mathrm{a}} \%$ [Men:Ac] of $\mathrm{Fe}^{2+}$ ions inhibition. Pure DES have no other molecules than menthol and lactic acid; thus they were able to form stable complexes with the metal from analysis, the ferrozine. Also, the viscosity of DES reinforces the stability of the chelates formed, which are superior to conventional solvents.

Schimidt and co-workers (Schmidt Erich Bail et al., 2009) showed that peppermint oil menthol was a scavenger of hydroxyl radicals and manifested chelating properties. Begqvist and co-authors (Bergqvist, Andlid, \& Sandberg, 2006) found that carrot juices exhibited more $\mathrm{Fe}^{2+}$ soluble ions after lactic acid fermentation. Around one-third of it remained after the in vitro digestion, suggesting protection of complexes made by lactic acid.

\subsubsection{Antibacterial activity}

Determining the extracts' ability to inhibit or reduce microbiological growth allows us to evaluate its potential for application as an additive in food for its preservation.

Table 2 presents the results of antibacterial activity for the extracts obtained from rhizomes, leaves, and flowers of Curcuma longa L., and the pure DES activity. The disk-diffusion method is a suitable visual method to evaluate bacteria inhibition, as shown in the photos of Fig. S2 (see supplementary material). Five bacteria of interest in the food industry have been tested, suggesting possible applications of the extracts studied in food preservation, edible coating, and biofilms.

From the forty essays performed, among samples of extracts and pure DES, nineteen essays exhibited susceptibility ( $\mathrm{S} \geq 17 \mathrm{~mm}$ ) (Table 2). Twelve were for gram-positive bacteria (Listeria monocytogenes, Clostridium perfringens, Staphylococcus aureus) and seven for gram-negative
(Escherichia coli and Salmonella sp.). This fact is quite normal due to the circumstance that gram-positive bacteria do not present an external membrane in their structure. Naturally, display less resistance to preservative mechanisms and are reachable to small and bioactive molecules (Brul \& Coote, 1999), intrinsic to extracts.

To the best of our knowledge, there are no results in the literature for the antibacterial activity of DES-based extracts from rhizomes, leaves, and flowers of Curcuma longa $L$. and pure hydrophobic DES. Extract obtained from leaves + Men:Ac DES showed activity that could be statistically compared to the antibiotic. Comparing the sample's inhibition with the antibiotic generated percentages above $50 \%$ for most of the samples, except for DES (Men:Ac) and rhizome extracts for both DES, within the $C$. perfringens bacteria. Observing the percentages, the most inhibited bacteria was L. monocytogenes, by Men:Lac-DES samples (bold values in Table 2), mostly from leaves and flowers, which was corroborated by the high iron-chelating capacities found.

Although lactic acid is associated with the antibacterial activity found for this specific DES, the menthol compound is responsible. Trombetta and co-workers (Trombetta et al., 2005) stated menthol as effective against $E$. coli than $S$. aureus. Its combination with lactic acid gave a good results here, suggesting a synergic effect of both in the hydrophobic DES Men:Lac.

\subsubsection{Acetylcholinesterase (AChE) and butyrylcholinesterase (BChE) inhibitory activity}

To evaluate the ability of bioactive compounds to alter the activity of cholinesterase enzymes can contribute to the treatment of diseases such as Alzheimer's and Parkinson's. The inhibition of these enzymes becomes something interesting since studies suggest that this is how the prevention of aging and dementia occurs, in addition to being involved in some diseases like Alzheimer's (Araújo, Santos, \& Gonsalves, 2016).

The effect of extracts on the activity of enzyme cholinesterase is shown in Table 3. In the samples with the rhizomes, it is possible to observe that the extracts with the Men:Lac showed an inhibition percentage of 84.32 and $99.24 \%$ for the enzyme BChE and AChE concerning control values (100\%). For those containing the Men:Ac extracts, this percentage decreased in both enzymes, 20.85 and $37.84 \%$, BChE and AChE, respectively. In extracts containing leaves samples, the solvent

Table 2

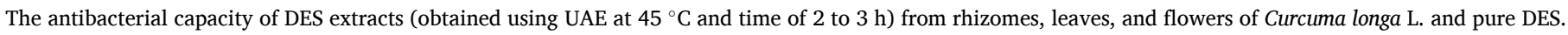

\begin{tabular}{|c|c|c|c|c|c|c|c|c|c|}
\hline \multirow[t]{2}{*}{ Bacteria } & \multicolumn{9}{|l|}{ Men:Lac extract } \\
\hline & Rhizome (mm) & $\mathrm{R} / \mathrm{I} / \mathrm{S}$ & $\%$ & Leaf (mm) & $\mathrm{R} / \mathrm{I} / \mathrm{S}$ & $\%$ & Flower (mm) & $\mathrm{R} / \mathrm{I} / \mathrm{S}$ & $\%$ \\
\hline Listeria monocytogenes & $21.4^{\mathrm{d}} \pm 0.4$ & S & 77 & $23.7^{b, c} \pm 0.1$ & $\mathbf{S}$ & 84 & $22.3^{\mathrm{cd}} \pm 0.3$ & $\mathbf{S}$ & 79 \\
\hline Clostridium perfringens & $13^{c} \pm 1$ & $\mathrm{R}$ & 45 & $18^{\mathrm{b}} \pm 1$ & I & 63 & $18^{\mathrm{b}} \pm 1$ & I & 62 \\
\hline Staphylococcus aureus & $20^{c} \pm 1$ & $S$ & 66 & $21^{\mathrm{bc}} \pm 1$ & $S$ & 71 & $21.6^{\mathrm{b}} \pm 0.2$ & $S$ & 73 \\
\hline Escherichia coli & $16.8^{c} \pm 0.3$ & I & 59 & $15.1^{\mathrm{d}} \pm 0.2$ & I & 52 & $18.7^{\mathrm{b}} \pm 0.2$ & $\mathrm{~S}$ & 65 \\
\hline Salmonella sp. & $20^{\mathrm{b}} \pm 1$ & $\mathrm{~S}$ & 69 & $18.8^{\mathrm{b}} \pm 0.4$ & $\mathrm{~S}$ & 63 & $20.2^{\mathrm{b}} \pm 0.4$ & S & 68 \\
\hline \multirow[t]{2}{*}{ Bacteria } & Men:Ac extract & & & & & & & & \\
\hline & Rhizome (mm) & $\mathrm{R} / \mathrm{I} / \mathrm{S}$ & $\%$ & Leaf (mm) & $\mathrm{R} / \mathrm{I} / \mathrm{S}$ & $\%$ & Flower (mm) & $\mathrm{R} / \mathrm{I} / \mathrm{S}$ & $\%$ \\
\hline Listeria monocytogenes & $14^{\mathrm{D}} \pm 1$ & I & 50 & $18.1^{\mathrm{B}} \pm 0.1$ & $S$ & 64 & $21.5^{\mathrm{B}} \pm 0.4$ & $\mathrm{~S}$ & 76 \\
\hline Clostridium perfringens & $8.3^{\mathrm{D}} \pm 0.2$ & $\mathrm{R}$ & 30 & $14.9^{\mathrm{BC}} \pm 0.3$ & I & 53 & $15.5^{\mathrm{B}} \pm 0.3$ & I & 55 \\
\hline Staphylococcus aureus & $12.2^{C} \pm 0.4$ & I & 41 & $30^{\mathrm{A}} \pm 1$ & $\mathrm{~S}$ & 99 & $21.0^{\mathrm{B}} \pm 0.4$ & $S$ & 71 \\
\hline Escherichia coli & $12^{\mathrm{C}} \pm 1$ & $\mathrm{R}$ & 42 & $16^{\mathrm{B}} \pm 1$ & I & 55 & $14^{\mathrm{B}} \pm 1$ & I & 50 \\
\hline Salmonella sp. & $18.6^{\mathrm{B}} \pm 0.2$ & $S$ & 62 & $17^{\mathrm{B}} \pm 1$ & I & 57 & $19.4^{\mathrm{B}} \pm 0.4$ & $S$ & 65 \\
\hline BACTERIA & Men:Lac & $\mathrm{R} / \mathrm{I} / \mathrm{S}$ & $\%$ & Antibiotic & $\mathrm{R} / \mathrm{I} / \mathrm{S}$ & $\%$ & Men:Ac & $\mathrm{R} / \mathrm{I} / \mathrm{S}$ & $\%$ \\
\hline Listeria monocytogenes & $25.0^{b} \pm 0.4$ & $S$ & 88 & $28^{\mathrm{aA}} \pm 1$ & $S$ & $100 \%$ & $18^{\mathrm{B}} \pm 1$ & I & 62 \\
\hline Clostridium perfringens & $16^{\mathrm{b}} \pm \overline{1}$ & I & 58 & $28^{\mathrm{aA}} \pm 2$ & $\mathrm{~S}$ & & $13^{C} \pm 0.1$ & I & 47 \\
\hline Staphylococcus aureus & $22.6^{\mathrm{b}} \pm 0.2$ & $S$ & 76 & $30^{\mathrm{aA}} \pm 1$ & $S$ & & $12^{\mathrm{C}} \pm 1$ & $\mathrm{R}$ & 39 \\
\hline Escherichia coli & $15^{\mathrm{d}} \pm 1$ & I & 52 & $29^{\mathrm{aA}} \pm 1$ & $S$ & & $11^{\mathrm{C}} \pm 1$ & $\mathrm{R}$ & 36 \\
\hline Salmonella sp. & $21.0^{\mathrm{b}} \pm 0.4$ & $S$ & 68 & $29^{\mathrm{aA}} \pm 1$ & $\mathrm{~S}$ & & $12^{\mathrm{C}} \pm 1$ & $\mathrm{R}$ & 39 \\
\hline
\end{tabular}

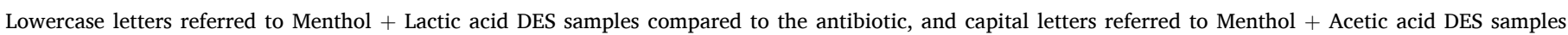
compared to antibiotic (ANOVA; LSD test, $p<0.05$ ).

$\mathrm{S}=$ susceptible $>18 \mathrm{~mm}$.

$\mathrm{I}=$ intermediate 13 to $17 \mathrm{~mm}$.

$\mathrm{R}=$ resistant $<12 \mathrm{~mm}$.

Source: CLSI et al. (2017). 
Table 3

Acetylcholinesterase (AChE) and butyrylcholinesterase (BChE) inhibitory activity capacity of DES extracts (obtained using UAE at $45^{\circ} \mathrm{C}$ and time of 2 to $3 \mathrm{~h}$ ) from rhizomes, leaves, and flowers of Curcuma longa L. and pure DES (all extracts were diluted $100 \times$ in methanol).

\begin{tabular}{|c|c|c|c|c|c|c|c|c|}
\hline \multirow[t]{2}{*}{ Samples } & \multicolumn{2}{|c|}{ Rhizomes } & \multicolumn{2}{|c|}{ Leaves } & \multicolumn{2}{|c|}{ Flowers } & \multicolumn{2}{|l|}{ DES } \\
\hline & $\begin{array}{l}\text { Men: } \\
\text { Lac }\end{array}$ & $\begin{array}{l}\text { Men: } \\
\text { Ac }\end{array}$ & $\begin{array}{l}\text { Men: } \\
\text { Lac }\end{array}$ & $\begin{array}{l}\text { Men: } \\
\text { Ac }\end{array}$ & $\begin{array}{l}\text { Men: } \\
\text { Lac }\end{array}$ & $\begin{array}{l}\text { Men: } \\
\text { Ac }\end{array}$ & $\begin{array}{l}\text { Men: } \\
\text { Lac }\end{array}$ & $\begin{array}{l}\text { Men: } \\
\text { Ac }\end{array}$ \\
\hline $\begin{array}{r}\text { BChE I } \\
(\%)^{\mathrm{a}}\end{array}$ & $\begin{array}{l}84 \pm \\
1^{\mathrm{a}}\end{array}$ & $\begin{array}{l}21 \pm \\
2^{f}\end{array}$ & $\begin{array}{l}82 \pm \\
4^{c}\end{array}$ & $\begin{array}{l}22 \pm \\
4^{d}\end{array}$ & $\begin{array}{l}84 \pm \\
4^{b}\end{array}$ & $\begin{array}{l}20 \pm \\
2^{\mathrm{g}}\end{array}$ & $\begin{array}{l}60 \pm \\
5^{\mathrm{e}}\end{array}$ & $\begin{array}{l}13 \pm \\
4^{\mathrm{h}}\end{array}$ \\
\hline $\begin{array}{c}\text { AChE I } \\
(\%)^{\mathrm{a}}\end{array}$ & $\begin{array}{l}99 \pm \\
1^{\mathrm{a}}\end{array}$ & $\begin{array}{l}38 \pm \\
5^{\mathrm{e}}\end{array}$ & $\begin{array}{l}99 \pm \\
1^{\mathrm{a}}\end{array}$ & $\begin{array}{l}30 \pm \\
4^{\mathrm{f}}\end{array}$ & $\begin{array}{l}98 \pm \\
1^{\mathrm{b}}\end{array}$ & $\begin{array}{l}6 \pm \\
1^{g}\end{array}$ & $\begin{array}{l}96 \pm \\
1^{c}\end{array}$ & $\begin{array}{l}95 \pm \\
1^{\mathrm{d}}\end{array}$ \\
\hline
\end{tabular}

The letters above the lines represent the results of ANOVA (LSD test; $p<0.05$ ). Same letters mean no significant difference.

a Percentage of Inhibition compared to control (media; standard deviation (SD); $n=4)$.

changed the inhibition values; as for rhizomes, extracts with Men: Lac showed more significant inhibition when compared with Men: Ac (81.92\% for BChE and $99.09 \%$ for AChE).

Regarding the samples containing the Curcuma longa L. flowers, for the Men:Lac system, there was no significant difference in the percentage of inhibition, in both enzymes, with $83.79 \%$ (BChE) and $97.94 \%$ (AChE). For Men:Ac, the extracts with flowers showed values of inhibition of 21.82 and $30.43 \%$ for BChE and AChE, respectively.

The Men:Lac DES showed inhibition values for the enzymes of 59.24 and $96.30 \%, \mathrm{BChE}$, and AChE, respectively. The extracts containing Men:Lac and all parts of the evaluated plant (rhizome, leaves, and flowers) increased the potential for inhibition of both enzymes in this solvent. For Men:Ac, the percentage of inhibition was $12.65 \%$ for $\mathrm{BChE}$ and $95.14 \%$ for AChE. The inhibition potential of the BChE enzyme increased with the addition of rhizome, leaves, and flowers. For the AChE enzyme, all values decreased.

Abbasi et al. (2012) evaluated the effect of curcumin (extracted from Curcuma rhizomes) on the activities of AChE and BChE. However, to date, there are no reports in the literature investigating the effects of extracts from these roots, leaves, and flowers composed of DES in the activities of these enzymes. Cholinesterase enzymes, such as acetyl and butyryl cholinesterase, hydrolyze the acetylcholine neurotransmitter (ACh) in acetate and choline, being present in different parts of the human body.

According to literature, curcumin, the most abundant curcuminoids present in Curcuma longa L., has antioxidant and antibacterial activity (Santos et al., 2020; S. Silva et al., 2019), in addition to the ability to inhibit the enzymatic activity of acetylcholinesterase and butyrylcholinesterase (Silva de Sá et al., 2019). Based on this characteristic and the results presented, it is possible to conclude that the DES was able to extract and preserve the biological activities of the extracts obtained from the rhizome, leaves, and flowers of Curcuma.

\subsubsection{Cytotoxicity and genotoxicity in Allium cepa L. cells}

Analyzing the cytotoxic potential of extracts in Allium cepa cells aims to ensure their safety for future applications in products for human consumption.

Table 4 shows MI (\%) results in root meristems of Allium cepa exposed to DES (Men:Lac and Men:Ac) extracts of rhizome, leaves, or flowers of Curcuma longa $\mathrm{L}$., at $24 \mathrm{~h}$ and $48 \mathrm{~h}$ exposure times. There was no difference between the mitotic indices for each exposure time within the same treatment in all evaluated samples (extracts with rhizomes, leaves, and flowers, in both solvents). There were no differences between the cell division indexes obtained for each exposure time for the same treatment and the mitotic index observed for the exposure times and the control. Therefore, none of the treatments evaluated for rhizome, leaves, flowers, DES, and control caused cytotoxicity to the meristematic cells of the meristem in the root of $A$. cepa.
Table 4

Mitotic indices (\%) and indices of cellular changes observed in root meristems of A. cepa exposed to DES extracts (obtained using UAE at $45{ }^{\circ} \mathrm{C}$ and time of 2 to 3 h) from rhizomes, leaves, and flowers of Curcuma longa L. and pure DES.

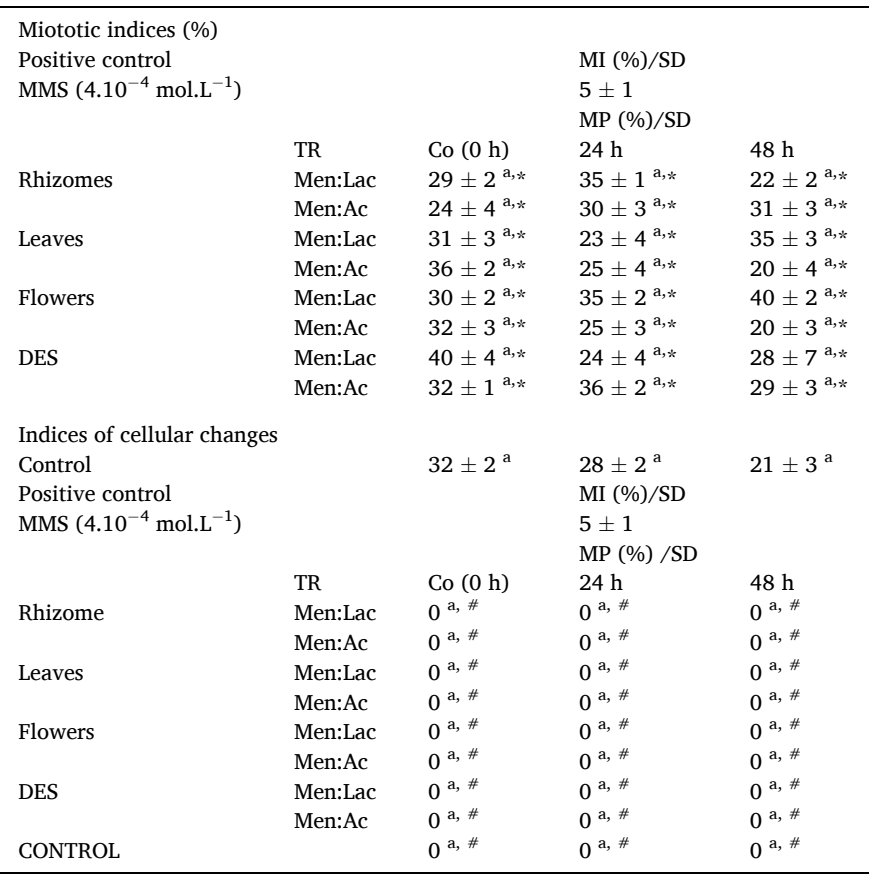

Co: control; MI: mitotic index; TR: treatment; h: hour. FCC: frequency of cellular changes. Analysis of variance (ANOVA), means compared by the Scott-Knott test at 0.05 . The same letters refer to similar results means between the exposure times considered (Co- 0 h, $24 \mathrm{~h}$, and $48 \mathrm{~h}$ ) at the same treatment. Different letters refer to different means between the exposure times considered (Co- 0 h, $24 \mathrm{~h}$, and $48 \mathrm{~h}$ ) within the same treatment. SD: Standard deviations reported for each analysis time evaluated for each concentration. *Mitotic index equal to the mitotic index observed for the control for the same analysis time. ${ }^{\#}$ Indices of cellular changes equal to the Indices of cellular changes for the control for the same analysis time.

Worth noticing that none of the evaluated treatments (Men:Lac and Men:Ac - extracts of rhizome, leaves or flowers and control) induced aneugenic changes and mitotic cell spindle meristemics of $A$. cepa root, proving to be non-genotoxic, at all times of evaluation (0,24 and $48 \mathrm{~h}$ ).

For the cytotoxicity and genotoxicity evaluation tests, the roots of Allium cepa $\mathrm{L}$. were used, because this species is internationally accepted for toxicogenetic tests of interest substances. The biomarkers applied in this study were the mitotic index (cell division index) to assess different cytotoxicity levels, and the frequency of chromosomal and mitotic spindle changes, to assess genotoxicity (de Silva et al., 2020; Herrero et al., 2012). The results obtained through the $A$. cepa bioassay have a good correlation with the results observed in genetic tests carried out in other bioassays, such as those with mammals and in cell culture (Herrero et al., 2012; Sales et al., 2018). Within the same treatment - Rhizome, flowers, leaves, or DES - the values of Men:Lac and Men:Ac - were the same, considering the same exposure time. With the results of nontoxicity for the extracts, there is an indication that these bio-based materials can be applied safely in food, cosmetics, and pharmaceutical products intended for humans.

Therefore, based on the biological activities presented, it is possible to state that the DES were effective in the extraction and preservation of bioactive compounds obtained from the rhizome, leaf, and flowers of Curcuma longa $\mathrm{L}$, and the extracts enhanced the capacity of the biological activities of DES. Also, the results showed that both pure DES and extracts obtained are potentially safe for use in food. 


\section{Conclusion}

Unprecedented extracts from rhizomes, leaves, and flowers of Curcuma longa L. with hydrophobic deep eutectic solvents (DES) were successfully proposed and evaluated. All DES tested showed superior extraction yield compared to the conventional solvent (ethanol) and the hydrophobic DES (menthol + lactic acid and menthol + acetic acid, 2:1 and 1:1 $\mathrm{M}$ ratio, respectively), had a greater extraction capacity when compared to the other DES. The outstanding extraction conditions were temperature of $45{ }^{\circ} \mathrm{C}$ and times from $2 \mathrm{~h}$ to $3 \mathrm{~h}$.

The biological activities for iron chelation and antibacterial activity highlighted extracts of flowers and leaves, and pure DES Men:Lac. Pure Men:Lac DES and its extracts showed inhibition values above $45 \%$ for all bacteria tested compared to antibiotic capacity, and iron chelation capacities were superior to $50 \%$. It was the first study to evaluate hydrophobic DES in antibacterial and iron-chelating abilities and demonstrated substantial values.

Furthermore, the extracts of Men: Lac showed more significant inhibitory potential in the enzymes AChE and BChE activities compared with the extracts of Men: Ac. The pure DES Men: Lac and Men:Ac had the same behavior. In general, there was a more significant inhibition of the enzymatic activity of AChE than BChE of all samples evaluated. Most important, no extracts were toxic to $A$. cepa cells, the first indication of using hydrophobic DES-based extracts of turmeric in food for human consumption in a safe way. Finally, the extracts from rhizomes, leaves, and flowers of Curcuma longa L. and hydrophobic DES are bio-based materials with great potential for application in the food, cosmetic and pharmaceutical industries.

\section{Declaration of Competing Interest}

The authors declare that they have no known competing financial interests or personal relationships that could have appeared to influence the work reported in this paper.

\section{Acknowledgments}

This study was financed by the Coordenação de Aperfeiçoamento de Pessoal de Nível Superior - Brasil (CAPES) - Finance Code 001. The authors thank both CAPES for the financial support, the Federal University of Paraná (UFPR) and the Federal University of Technology Paraná (UTFPR), Labmulti-CM (UTFPR) for the technical support provided. M. R. Mafra and L. Igarashi-Mafra are grateful to the Brazilian National Council for Scientific and Technological Development (CNPq Grant 310182/2018-2 and 308517/2018-0, respectively).

\section{Appendix A. Supplementary data}

Supplementary data to this article can be found online at https://doi. org/10.1016/j.ifset.2021.102697.

\section{References}

Abbasi, M. A., Ilyas, M., Aziz-Ur-Rehman Sonia, A., Shahwar, D., Raza, M. A., Khan, K. M., ... Ambreen, N. (2012). Curcumin and its derivatives: Moderate inhibitors of acetylcholinesterase, butyrylcholinesterase and trypsin. Scientia Iranica, 19(6), 1580-1583. https://doi.org/10.1016/j.scient.2012.10.014

Abbott, A. P., Capper, G., Davies, D. L., Rasheed, R. K., \& Tambyrajah, V. (2003). Novel solvent properties of choline chloride/urea mixtures. Chemical Communications (Cambridge, England), 1, 70-71. https://doi.org/10.1039/b210714g

Ak Tuba, I. G. (2008). Antioxidant and radical scavenging properties of curcumin. Chemico-Biological Interactions, 174, 27-37. https://doi.org/10.1016/j. cbi.2008.05.003

Altunay, N., Elik, A., \& Gürkan, R. (2020). Preparation and application of alcohol based deep eutectic solvents for extraction of curcumin in food samples prior to its spectrophotometric determination. Food Chemistry, 310, 125933. https://doi.org/ 10.1016/j.foodchem.2019.125933 (March 2019).

Araújo, C. R. M., Santos, V. L. A., \& Gonsalves, A. A. (2016). Acetylcholinesterase - AChE: A pharmacological interesting enzyme. Revista Virtual de Quimica, 8(6), 1818-1834. https://doi.org/10.21577/1984-6835.20160122
Aydin, F., Yilmaz, E., \& Soylak, M. (2018). Vortex assisted deep eutectic solvent (DES) -emulsi fi cation liquid-liquid microextraction of trace curcumin in food and herbal tea samples. Food Chemistry, 243, 442-447. https://doi.org/10.1016/j. foodchem.2017.09.154 (October 2017).

Bajkacz, S., \& Adamek, J. (2017). Talanta evaluation of new natural deep eutectic solvents for the extraction of isoflavones from soy products. Talanta, 168, 329-335. https://doi.org/10.1016/j.talanta.2017.02.065 (August 2016).

Bavarsad, K., Matbou, M., Saadat, S., \& Barreto, G. (2019). Protective effects of curcumin against ischemia-reperfusion injury in the liver. Pharmacological Research, 141, 53-62. https://doi.org/10.1016/j.phrs.2018.12.014 (December 2018).

Bergqvist, S. W., Andlid, T., \& Sandberg, A. (2006). Lactic acid fermentation stimulated iron absorption by Caco-2 cells is associated with increased soluble iron content in carrot juice. The British Journal of Nutrition, 96, 705-711. https://doi.org/10.1079/ BJN20061905

Borah, A., Hazarika, K., \& Khayer, S. M. (2015). Drying kinetics of whole and sliced turmeric rhizomes (Curcuma longa L.) in a solar conduction dryer. Information Processing in Agriculture, 2(2), 85-92. https://doi.org/10.1016/j.inpa.2015.06.002

Braga, M. C., Caroline, E., Vieira, S., \& De Oliveira, T. F. (2018). Curcuma longa L. leaves: Characterization (bioactive and antinutritional compounds) for use in human food in Brazil. Food Chemistry, 265(January), 308-315. https://doi.org/10.1016/j. foodchem.2018.05.096

Brul, S., \& Coote, P. (1999). Preservative agents in foods mode of action and microbial resistance mechanisms. International Journal of Food Microbiology, 50, 1-17.

Chan, E. W. C., Lim, Y. Y., Wong, S. K., Lim, K. K., Tan, S. P., Lianto, F. S., \& Yong, M. Y. (2009). Effects of different drying methods on the antioxidant properties of leaves and tea of ginger species. Food Chemistry, 113(1), 166-172. https://doi.org/ 10.1016/j.foodchem.2008.07.090

Chatzinasiou, L., Booker, A., Heinrich, M., Maclennan, E., \& Mackonochie, M. (2019). Turmeric (Curcuma longa L.) products: What quality differences exist? Journal of Herbal Medicine, 100281. https://doi.org/10.1016/j.hermed.2019.100281, 17-18 (February).

CLSI, Dolinsky, A. L., Ohiro, R. K., Fan, W., Xiao, C., \& Wu, F. (2017). National Committee for Clinical Laboratory Standards. 2000. Performance standard for antimicrobial susceptibility testing. Document M100-S10. In P. Institute, Clinical and Laboratory Standards, Wayne (Ed.), Journal of International Medical Research (27th ed., Vol. 46, Issue September). https://doi.org/10.1108/08876049410065598

Courtney, K. D., \& Francisco, S. (1961). A new and rapid colorimetric of acetylcholinesterase determination. Biochemical Pharmacology, 7, 88-95. https://doi. org/10.1016/0006-2952(61)90145-9

Cunha, F. A. B., Pinho, A. I., Santos, J. F. S., Sobral-souza, C. E., Albuquerque, R. S., Matias, E. F. F., ... Waczuk, E. P. (2019). Cytoprotective effect of Eugenia uniflora L. against the waste contaminant mercury chloride. Arabian Journal of Chemistry, 4197-4203. https://doi.org/10.1016/j.arabjc.2016.04.018

Dai, Y., Van Spronsen, J., \& Witkamp, G. (2013). Analytica chimica acta natural deep eutectic solvents as new potential media for green technology. Analytica Chimica Acta, 766, 61-68. https://doi.org/10.1016/j.aca.2012.12.019

Fiskesjö, G. (1993). The Allium Test - A Potential Standard for the Assessment of Environmental Toxicity. Environmental Toxicology and Risk Assessment, 2, 331-345. https://doi.org/10.1520/STP13165S

Florindo, C., Branco, L. C., \& Marrucho, I. M. (2017). Fluid phase equilibria development of hydrophobic deep eutectic solvents for extraction of pesticides from aqueous environments. Fluid Phase Equilibria, 448, 135-142. https://doi.org/10.1016/j. fluid.2017.04.002

Grover, M., Shah, K., Khullar, G., Gupta, J., \& Behl, T. (2019). Investigation of the utility of Curcuma caesia in the treatment of diabetic neuropathy. Journal of Pharmacy and Pharmacology, 71, 725-732. https://doi.org/10.1111/jphp.13075

Gülçin, I. (2006). Antioxidant activity of caffeic acid 3, 4-dihydroxycinnamic acid. Toxicology, 217, 213-220. https://doi.org/10.1016/j.tox.2005.09.011

Hammond, P. S., \& Forster, J. S. (1989). A microassay-based procedure for measuring low levels of toxic organophosphorus compounds through Acetylcholinesterase inhibition 1. Analytical, 3, 380-383.

Herrero, O., Pérez Martín, J. M., Fernández Freire, P., Carvajal López, L., Peropadre, A., \& Hazen, M. J. (2012). Toxicological evaluation of three contaminants of emerging concern by use of the Allium cepa test. Mutation Research, Genetic Toxicology and Environmental Mutagenesis, 743(1-2), 20-24. https://doi.org/10.1016/j. mrgentox.2011.12.028

Khezeli, T., Daneshfar, A., \& Sahraei, R. (2016). Talanta A green ultrasonic-assisted liquid - liquid microextraction based on deep eutectic solvent for the HPLC-UV determination of ferulic, caffeic and cinnamic acid from olive, almond, sesame and cinnamon oil. Talanta, 150, 577-585. https://doi.org/10.1016/j. talanta.2015.12.077

Kirikta, H., Mehmet, S., Eslek, S., \& Kirikta, İ. (2018). A new approach to determine the density of liquids and solids without measuring mass and volume: Introducing the solidensimeter.

Kwiecien, S., Magierowski, M., Majka, J., \& Ptak-belowska, A. (2019). Curcumin: A potent protectant against esophageal and gastric disorders. International Journal of Molecular Sciences, 20. https://doi.org/10.3390/ijms20061477

Liu, Y., Li, J., Fu, R., Zhang, L., Wang, D., \& Wang, S. (2019). Industrial crops \& products enhanced extraction of natural pigments from Curcuma longa L. using natural deep eutectic solvents. Industrial Crops and Products, 140, 111620. https://doi.org/ 10.1016/j.indcrop.2019.111620 (May).

Makoś, P., Słupek, E., \& Gebicki, J. (2020). Hydrophobic deep eutectic solvents in microextraction techniques - A review. Microchemical Journal, 152, 104384. https:// doi.org/10.1016/j.microc.2019.104384 (October 2019). 
Mandal, V., Dewanjee, S., Sahu, R., \& Mandal, S. C. (2009). Design and optimization of ultrasound assisted extraction of Curcumin as an effective alternative for conventional. Natural Product Communications, 4(1), 95-100.

Marques, C., Wojeicchowski, J. P., Cardoso, T., Mafra, M. R., Mitterer-Daltoé, M. L., \& Masson, M. L. (2020). Lactobionic acid as a suitable food preservative for yacon juice. Innovative Food Science and Emerging Technologies, 64, 102400. https://doi.org/ 10.1016/j.ifset.2020.102400 (May).

Martins, M. A. R., Pinho, S. P., \& Coutinho, J. A. P. (2018). Insights into the nature of eutectic and deep eutectic mixtures. Journal of Solution Chemistry, 1-21. https://doi. org/10.1007/s10953-018-0793-1

Nelson, K. M., Dahlin, J. L., Bisson, J., Graham, J., Pauli, G. F., \& Walters, M. A. (2017) The essential medicinal chemistry of Curcumin. Journal of Medicinal Chemistry, 60, 1620-1637. https://doi.org/10.1021/acs.jmedchem.6b00975

Pal, K., Chowdhury, S., Kumar, S., Chakraborty, S., Chakraborty, M., Kumar, G., Dutta, S., Kumar, P., Choudhury, A., Majumder, B., Sahana, N., \& Mandal, S. (2020) Industrial crops \& products analysis of rhizome colour content, bioactive compound profiling and ex-situ conservation of turmeric genotypes (Curcuma longa L.) from sub- Himalayan terai region of India. Industrial Crops and Products, 150, 112401. https://doi.org/10.1016/j.indcrop.2020.112401 (March).

Patil, S. S., \& Rathod, V. K. (2020). Synergistic effect of ultrasound and three phase partitioning for the extraction of Curcuminoids from Curcuma longa and its bioactivity profile. Process Biochemistry, 93, 85-93. https://doi.org/10.1016/j. procbio.2020.02.031 (January).

Ribeiro, B. D., Florindo, C., Lucas, C. I., Coelho, M. A. Z., \& Marrucho, I. M. (2015). Menthol-based eutectic mixtures: Hydrophobic low viscosity solvents. ACS Sustainable Chemistry \& Engineering, 3, 2469-2477. https://doi.org/10.1021/ acssuschemeng.5b00532

Salehi, B., Stojanovi, Z., Mateji, J., Shari, M., Shari, J., \& Kumar, N. V. A. (2019). The therapeutic potential of curcumin: A review of clinical trials. European Journal of Medicinal Chemistry, 163. https://doi.org/10.1016/j.ejmech.2018.12.016

Sales, I. M. S., Silva, J. M., Moura, E. S. R., Alves, F. D. S., Silva, F. C. C., Sousa, J. M. C., \& Peron, A. P. (2018). Toxicity of synthetic flavorings, nature identical and artificial, to hematopoietic tissue cells of rodents. Brazilian Journal of Biology, 78(2), 306-310. https://doi.org/10.1590/1519-6984.07716

Santos, D. P. D. F., Coqueiro, A., Brum, S., Marchesan, S., Fernanda, O., Leimann, V., ... Hess, O. (2020). Endogenous antioxidant properties of curcuminoids from Curcuma longa L. obtained by a single-step extraction/nanoencapsulation approach. Journal of Food Biochemistry, 1-12. https://doi.org/10.1111/jfbc.13531. July.

Satomi, D., \& Terasaki Masanori, M. M. (2009). Acetylcholinesterase inhibitory activity and chemical composition of commercial essential oils. Journal of Agricultural and Food Chemistry, 57, 4313-4318. https://doi.org/10.1021/jf804013j
Scartezzini, P., \& Speroni, E. (2000). Review on some plants of Indian traditional medicine with antioxidant activity. Journal of Ethnopharmacology, 71, 23-43.

Schmidt Erich Bail, S., Buchbauer, G., Stoilova, I., Atanasovad, T., Stoyanova, A., Krastanov, A., \& Jirovetz, L. (2009). Chemical composition, olfactory evaluation and antioxidant effects of essential oil from mentha x piperita. Natural Product Communications, 4(8), 1107-1112. https://doi.org/10.1177/1934578X0900400819

Shirsath, S. R., Sable, S. S., Gaikwad, S. G., Sonawane, S. H., Saini, D. R., \& Gogate, P. R. (2017). Ultrasonics - Sonochemistry intensification of extraction of curcumin from Curcuma amada using ultrasound assisted approach: Effect of different operating parameters. Ultrasonics Sonochemistry, 38, 437-445. https://doi.org/10.1016/j. ultsonch.2017.03.040 (March).

Silva de Sá, I., Peron, A. P., Leimann, F. V., Bressan, G. N., Krum, B. N., Fachinetto, R., ... Ineu, R. P. (2019). In vitro and in vivo evaluation of enzymatic and antioxidant activity, cytotoxicity and genotoxicity of curcumin-loaded solid dispersions. Food and Chemical Toxicology, 125, 29-37. https://doi.org/10.1016/j.fct.2018.12.037 (November 2018)

Silva, S., Campos, D., De Oliveira, A., Fernandes, T., Moreira, M., Barlati, T., ... Vitória, F. (2019). TPCS/PBAT blown extruded fi lms added with curcumin as a technological approach for active packaging materials. Food Packaging and Shelf Life, 22, 100424. https://doi.org/10.1016/j.fpsl.2019.100424 (November).

de Silva, T. S., Silva, A. P. S. E., de Almeida Santos, A., Ribeiro, K. G., de Souza, D. C., Bueno, P. A. A., ... Peron, A. P. (2020). Cytotoxicity, genotoxicity, and toxicity of plant biostimulants produced in brazil: subsidies for determining environmental risk to non-target species. Water, Air, and Soil Pollution, 231(5). https://doi.org/10.1007/ s11270-020-04614-X

Skerget, M., Perko, T., \& Ravber, M. (2015). Isolation, characterization and formulation of curcuminoids and in vitro release study of the encapsulated particles. The Journal of Supercritical Fluids, 103, 48-54. https://doi.org/10.1016/j.supflu.2015.04.023

Soni, H., Patel, S. S., \& Pradesh, M. (2011). Qualitative and quantitative profile of curcumin from ethanolic extract of Curcuma longa. International Research Journal of Pharmacy, 4, 180-184 (November 2010).

Trombetta, D., Castelli, F., Sarpietro, M. G., Venuti, V., Cristani, M., Daniele, C., ... Bisignano, G. (2005). Mechanisms of antibacterial action of three monoterpenes. Antimicrobial Agents and Chemotherapy, 49(6), 2474-2478. https://doi.org/10.1128/ AAC. 49.6.2474

Vilková, M., Justyna, P., \& Andruch, V. (2020). The role of water in deep eutectic solvent-base extraction. Journal of Molecular Liquids, 304. https://doi.org/10.1016/j. molliq.2020.112747

Zhang, Q., Oliveira, K. V., Royer, S., Royer, \& Jérôme, F. (2012). Chem Soc rev. Chemical Society Reviews, 41, 7108-7146. https://doi.org/10.1039/c2cs35178a 